\title{
TUNAS
}

JURNAL PENDIDIKAN GURU SEKOLAH DASAR

http://journal.umpalangkaraya.ac.id/index.php/tunas

Volume 5 Nomor 1, Desember 2019 (1-6)

\section{UPAYA MENINGKATKAN HASIL BELAJAR IPA MENGGUNAKAN METODE PROBLEM SOLVING BERIOLABORASI DENGAN METODE EKSPERIMEN PADA PESERTA DIDIK KELAS III DI SD ISLAM NURUL IHSAN PALANGKARAYA}

Efforts To Improve Ipa Learning Outcomes Using Collaboration Problem Solving Method With Experimental Methods In Grade III Students In Islamic Elementary School Nurul Thsan Palangkaraya

'Endang Sri Estimurti dan ${ }^{2}$ Siti Raudah

Universitas Muhammadiyah Palangkaraya, Palangka Raya, Kalimantan Tengah, Indonesia

¿Universitas Muhammadiyah Palangkaraya, Palangka Raya, Kalimantan Tengah, Indonesia

\section{ARTIKEL INFO}

Diterima

November 2019

Dipublikasi

Desember 2019

*e-mail :

Endangsriestimurtil @gm ail.com

\section{ABSTRAK}

Penelitian ini bertujuan untuk mengetahui : (I) Aktivitas peserta didik kelas III SD Islam Nurul Ihsan Palangka Raya pada saat Pembelajaran IPA dengan menggunakan Metode Problem Solving berkaloborasi dengan Metode Eksperimen dan (2) Meningkatkan hasil belajar IPA dengan menggunakan Metode Problem Solving berkaloborasi dengan Metode Eksperimen pada peserta didik kelas III SD Islam Nurul Ihsan Plangka Raya. Metode yang digunakan peneliti adalah Penelitian Tindakan Kelas (PTK) dengan subjek penelitian 28 peserta didik yang terdiri dari I 3 laki-laki dan 15 perempuan kelas III SD Islam Nurul Ihsan Palangka Raya. Teknik pengumpulan data dalam penelitian ini menggunakan observasi dan tes. Analisis data menggunakan analisis data kualitatif dan kuantitatif. Hasil penelitian ini menunjukkan bahwa : (I) Aktivitas peserta didik kelas III SD Islam Nurul Ihsan Palangka Raya pada saat pembelajaran berlangsung dengan menggunakan metode Problem Solving berkaloborasi dengan metode Eksperimen pada mata pelajaran IPA materi Energi sudah dalam kategori sangat baik. (2) Ada peningkatan hasil belajaran IPA dengan menggunakan metode Problem Solving berkaloborasi dengan metode Eksperimen pada peserta didik kelas III SD Islam Nurul Ihsan Palangka Raya. Hal ini dapat dilihat dari hasil belajar peserta didik, pada pre test dengan rat-rata 48,4 dengan ketuntasan klasikal 17\%, sedangkan hasil post test siklus I rata-rata 76,7 dengan ketuntasan klasikal yaitu $100 \%$.

Kata kunci: IPA, Metode Problem Solving berkolaborasi dengan Metode Eksperimen

\section{ABSTRACT}

The purpose of this research is to know: (I) The activity of thrird grade student of Islamic Elementary School of Nurul Ihsan Palangka Raya at the time of Science Learning using Problem Solving Method Asisted with Experimental Method and (2) Increase science learning result by using Problem Solving Method berkaloborasi with Experiment Method in the third grade students of Islamic Elementary School Nurul Ihsan Plangka Raya. The method used by researchers is Classroom Action Research (CAR) with the subject of 28 students consisting of 13 male and 15 famle class III Islamic Elementary School Nurul Ihsan Palangka Raya. Technique of collecting data in this research use observation and test. Data analysis used qualitative and quantitative data analysis. The results of this study indicate that: (I) The activity of thrird grade students of Islamic Elementary School Nurul Ihsan Palangka Raya at the time of learning took place by using Problem Solving method Asissted with Experimental method on science subjects Energy material is in very good category. (2) There is an increase in science learning outcomes by using Problem Solving method berkoboborasi with experimental methods on students thrird grade Islamic Elementary School Nurul Ihsan Palangka Raya. It can be seen from the students learning result, on pre test with 48,4 average with I $7 \%$ classical completeness, while post test result of cycle I average 76,7 with classical completeness is 100.

Keywords: IPA, Problem Solving Method collaborate with Experimental Method.

(C) Universitas Muhammadiyah Palangkaraya 
Jurnal Pendidikan Guru Sekolah Dasar PENDAHULUAN

Pendidikan bertujuan untuk mencerdaskan, mengembangkan kemampuan dan meningkatkan kualitas sumber daya manusia secara sadar dan disengaja, serta penuh tanggung jawab yang dilakukan oleh orang dewasa kepada anak didik sehingga timbul interaksi timbal balik di antara keduanya. Hal ini sesuai dengan tujuan pendidikan nasional yang dirumuskan dalam UU Sisdiknas No. 20 Tahun 2003, sebagaimana berikut : Pendidikan nasional berfungsi untuk mengembangkan kemampuan dan membentuk watak serta peradaban bangsa yang bermartabat dalam rangka mencerdaskan kehidupan bangsa, bertujuan untuk mengembangkan potensi peserta didik agar menjadi manusia yang beriman dan bertakwa kepada Tuhan yang Maha Esa, berakhlak mulia, sehat, berilmu, cakap, kreatif, mandiri dan menjadi warga negara yang demokratis serta bertanggung jawab.

Sejalan dengan tujuan pendidikan di atas, pendidikan memiliki peran dan pengaruh positif terhadap segala bidang kehidupan dan perkembangan manusia dengan berbagai aspek kepribadiannya. Pengaruh pendidikan dapat dilihat dan dirasakan secara langsung dalam perkembangan serta kehidupan masyarakat, kehidupan kelompok dan kehidupan setiap individu. Pendidikan berurusan langsung dengan pembentukan manusianya.

Pendidikan merupakan proses perubahan sikap dan tingkah laku seseorang dalam usaha mencapai pendewasaan diri. Peran pendidikan ini dapat terwujud, salah satunya adalah melalui pembelajaran. Pembelajaran yang dimaksud tentunya yang ditempuh seseorang pada suatu proses yang kompleks, yang didalamnya meliputi unsur manusia, material, fasilitas, perlengkapan dan prosedur yang saling mempengaruhi pencapaian tujuan pendidikan.

Pembelajaran berperan penting bagi pendidikan yang bisa dijadikan wahana untuk membangun watak seseorang yang dapat ditempuh melalui pengajaran dan pelatihan. Proses pengajaran dan pelatihan bisa ditempuh melalui pembelajaran yang dilaksanakan di bangku sekolah.

Dalam kegiatan pembelajaran, metode pembelajaran sangat dipelukan oleh guru, dengan penggunaan yang bevariasi sesuai dengan tujuan yang ingin dicapai. Menguasai metode pembelajaran merupakan keniscayaan sebab seorang guru tidak akan dapat mengajar dengan baik apabila tidak menguasai metode pembelajaran secara tepat. Salah satu usaha untuk meningkatkan kualitas tenaga pengajaran yaitu pendidik mampu menggunakan metode pembelajaran yang bervariasi dalam berbagai mata pelajaran. salah satunya mata pelajaran IPA.

$$
\text { Ilmu Pengetahuan Alam }
$$

menekankan pada pembelajaran pengalaman langsung, kontekstual, dan berpusat pada peserta didik serta berpikir kritis terhadap masalah yang terjadi di sekitarnya sehingga dapat diterapkan dalam kehidupan sehari-hari. Hal ini selaras Menurut Siregar dan Nara (2010 : 80) bahwa "metode pembelajaran didefinisikan sebagai cara yang digunakan guru, sehingga dalam menjalankan fungsinnya, Metode merupakan alat untuk mencapai tujuan pembelajaran". Disini guru diharapkan menggunakan Metode yang dapat menunjang kegiatan pembelajaran, sehingga peserta didik mudah memahami materi pembelajaran.

Berdasarkan observasi awal yang peneliti lakukan pada tanggal 23 januari 2018 yaitu pada proses pembelajaran IPA berlangsung dimana peserta didik kurang memahami materi pembelajaran yang disampaikan pendidik. Hal itu dikarenakan pada saat proses pembelajaran hanya menggunakan Metode ceramah dan tidak mengkolaborasikan dengan metode pembelajaran lain. Kurang melibatkan peserta 
Jurnal Pendidikan Guru Sekolah Dasar

didik secara langsung dalam pembelajran sehingga peserta didik tidak aktif dan menyebabkan situasi pembelajar kurang menyenangkan bagi peserta didik dan membuat peserta didik merasa bosan karena hanya mendengar tanpa melihat dan mengamati secara langsung materi yang dijelaskan pendidik. Hal tersebut membuat peserta didik kurang memperhatikan pembelajaran yang diberikan oleh pendidik, peserta didik sibuk bermain dengan teman sebangkunya, selain itu juga terlihat dari pendidik hanya menjelaskan materi pembelajaran yang ada dibuku paket saja. Serta penampilan pendidik menyampaikan pembelajaran juga kurang bervariasi dimana dalam pemusatan dan perubahan posisi pendidik dalam menyampaikan pembelajaran masih kurang. Hal ini juga terlihat dari hasil belajar peserta didik yang masih rendah pada pelajaran IPA. Dengan Kriteria Ketuntasan Minimum (KKM) adalah 65, dari seluruh peserta didik yang berjumlah 28 orang, ada 9 orang (35\%) yang mendapat nilai di atas 60 dan 19 orang (65\%) mendapat nilai di bawah KKM.

Salah satu upaya untuk memecahkan permasalahan di atas agar dapat menunjang peranan peserta didik agar lebih aktif dalam kegiatan belajar mengajar untuk meningkatkan hasil belajar IPA adalah menggunakan metode pembelajaran pemecahan masalah (problem solving) dan metode pembelajaran eksperimen. Metode pembelajaran pemecahan masalah (problem solving) merupakan salah satu dari sekian banyak metode pembelajaran yang kerap digunakan. Abdul Majid (2012 : 142) menyatakan bahwa :Metode pembelajaran pemecahan masalah (problem solving) merupakan cara memberikan pengertian-pengetian dengan menstimulasi anak didik untuk memperhatikan, menelaah dan berfikir tentang suatu masalah untuk selanjutnya menganalisis masalah tesebut sebagai upaya untuk memecahkan masalah.
Menurut Djamarah dan Zain (2010 : 84) bahwa "Metode pembelajaran eksperimen adalah cara penyajian pembelajaran, dimana peserta didik melakukan percobaan dengan mengalami dan membuktikan sendiri sesuatu yang dipelajari”. Pada hakekatnya metode pembelajaran eksperimen merupakan suatu teknik pembelajaran yang konkret dimana dalam pembelajaran yang digunakan untuk melakukan percobaan untuk melihat suatu hasil dengan menggunakan keahlian dari pendidk untuk merancang dan memanfaatkan alat-alat sederhana untuk melakukan eksperimen, dengan kata lain menggunakan Metode eksperimen dapat memunculkan kreatifitas dan mampu memberikan hasil belajar dan pembelajaran mudah diingat oleh peserta didik.

Oleh karena itu, pendidik juga dapat merancang pola belajar yang bervariasi yaitu dengan menggunakan metode pembelajaran eksperimen yang percobaanya disesuaikan dengan materi yang diajarkan. Dimana Metode eksperimen dapat membantu pendidik dalam menyampaikan materi dan peserta didik lebih mudah memahami materi pembelajaran dengan menggunakan suatu kegiatan percobaan.

Proses pembelajaran IPA diperlukan penyampaian informasi yang tepat agar peserta didik mampu menyerap ilmu yang terkandung didalamnya secara akurat. Informasi yang disalurkan melalui media pada umumnya dilambangkan dalam bentuk gambar, rekaman, film, tabel, peta, grafik, bagan, benda, dan lainlain.

Dalam hal ini peneliti menggunakan media konkret untuk menuntun dan membantu mengembangkan daya pikir dan imajinasi peserta didik pada saat membuat eksperimen karena dengan media konkret peserta didik dapat melihat langsung atau nyatanya. Disamping itu penggunaan media konkret dapat menimbulkan daya tarik bagi peserta didik serta memberikan

\footnotetext{
'Endang Sri Estimurti dan ${ }^{2}$ Siti Raudah 
Jurnal Pendidikan Guru Sekolah Dasar

inspirasi dalam melahirkan gagasan untuk menulis.

Penelitian ini penting karena, dengan adanya penelitian ini dapat memperbaiki proses dan kinerja pembelajaran IPA, dengan demikian penelitian ini juga diharapakan dapat meningkatkan aktivitas dan hasil belajar IPA pada peserta didik kelas III SD Islam Nurul Ihsan Palangkaraya.

\section{METODOLOGI PENELITIAN}

Penelitian ini dilaksanakan pada bulan Maret sampai dengan bulan Mei 2018, untuk lebih jelas dapat dilihat pada jadwal penelitian.

Penelitian ini di lakukan di kelas III di SD Islam Nurul Ihsan Palangka Raya Tahun Pembelajaran 20I7/20।8, yang beralamat di JI Dr. Murjani, Kec Pahandut, kota Palangkaraya Prov Kalimantan Tengah.

Penelitian ini menggunakan metode merupakan salah satu hal yang penting. Dengan adanya metode tertentu penelitian akan lebih terarah dan dapat dipertanggung jawabkan. Dalam penelitian ini menggunakan metode Penelitian Tindakan Kelas (PTK).

Subjek penelitian pada penelitian tindakan kelas disini yaitu seluruh peserta didik kelas III SD Islam Nurul Ihsan yang terdiri dari 13 orang lakilaki dan 15 perempuan yang seluruhnya berjumlah 28 orang peserta didik.

\section{HASIL DAN PEMBAHASAN}

Hasil pengamatan aktivitas guru dan peserta didik dalam kegiatan belajar mengajar dalam pembelajaran IPA dengan menggunakan metode problem solving berkolaborasi dengan metode ekperimen yang di nilai oleh observer saat kegiatan belajar mengajar sebagai berikut:

\section{Rekapitulasi Nilai Pengamatan}

Aktivitas Guru dan Peseta Didik Dalam KBM

\begin{tabular}{|l|l|l|}
\hline No & Aktivitas & $\begin{array}{l}\text { Rata-rata Nilai } \\
\text { Siklus I }\end{array}$ \\
\hline 1 & $\begin{array}{l}\text { Aktivitas } \\
\text { Guru }\end{array}$ & 3,8 \\
\hline 2 & $\begin{array}{l}\text { Aktivitas } \\
\text { Peserta } \\
\text { Didik }\end{array}$ & 3,8 \\
\hline
\end{tabular}

Nilai hasil belajar yang dimaksud ialah peningkatan nilai hasil belajar peserta didik kelas III SD Islam Nurul Ihsan Palangkaraya

yang menggunakan metode problem solving berkolaborasi dengan metode eskperimen pada materi Energi. Adapun perolehan hasil belajar siklus I adalah 100\% dengan rata-rata 77 . Hal ini dapat dilihat dari rata-rata nilai pra tindakan 49 dengan ketuntasan 17\%. Berikut ini rekapitulasi nilai hasil belajar peserta didik kelas III SD Islam Nurul Ihsan Palangkaraya.

\section{Hasil Ketuntasan Belajar}

\begin{tabular}{|l|l|l|}
\hline No & $\begin{array}{l}\text { Ketuntasan } \\
\text { Klasikal } \\
\text { Pra } \\
\text { Tindakan }\end{array}$ & $\begin{array}{l}\text { Ketuntasan } \\
\text { Klasikal } \\
\text { Siklus I }\end{array}$ \\
\hline 1 & $17 \%$ & $100 \%$ \\
\hline
\end{tabular}

Hasil belajar peserta didik kelas III SD Islam Nurul Ihsan mengalami peningkatan pada siklus I dengan memperoleh nilai secara klasikal yaitu $100 \%$ dengan ketuntasan klasikal minimal 85\%. 
Jurnal Pendidikan Guru Sekolah Dasar

\section{KESIMPULAN}

Hasil pengamatan aktivitas guru dan peserta didik dalam kegiatan belajar mengajar dalam pembelajaran IPA dengan menggunakan metode problem solving berkolaborasi dengan metode ekperimen yang di nilai oleh observer saat kegiatan belajar mengajar.

Nilai hasil belajar yang dimaksud ialah peningkatan nilai hasil belajar peserta didik kelas III SD Islam Nurul Ihsan Palangkaraya yang menggunakan metode problem solving berkolaborasi dengan metode eskperimen pada materi Energi. Adapun perolehan hasil belajar siklus I adalah $100 \%$ dengan rata-rata 77 . Hal ini dapat dilihat dari rata-rata nilai pra tindakan 49 dengan ketuntasan 17\%.

Hasil belajar peserta didik kelas III SD Islam Nurul Ihsan mengalami peningkatan pada siklus I dengan memperoleh nilai secara klasikal yaitu $100 \%$ dengan ketuntasan klasikal minimal 85\%.

\section{DAFTAR PUSTAKA}

Arikunto Suharsimin, (2010).Penelitian Tindakan Kelas, Jakarta : PT Bumi Aksara. , (2006).Dasardasar Evaluasi Pendidikan, Jakarta : Bumi Akasa

Basonggo Isna, dkk, (2012). Meningkatkan Hasil Belajar Siswa Melalui Metode Eksperimen dalam Pembelajaran IPA di Kelas V SDN Meselesek. Palu: Jurnal Kreatif Tadulako Online Vol. 2 No. 2 ISSN 2354-614X.
Depdiknas, (2003). Undang-Undang Tentang Sistem Pendidikan Nasional. Jakarta: Sekaeriat Negara.

Hartini Nara dan Eveline Siregar, (2014).Teori Belajar dan Pembelajaran, Bogor : Ghalia Indonesia.

Harmalik Oemar, (2010).Teori Pembelajaran, Jakarta: Indonesia

Ibrahim dan Syaodih ,(2013). Perencanaan Pengajaran. Jakarta: Rineka Cipta

Kurt Lewin, (2014). Peneltian PTK Model Kurt Lewin. Jakarta: Rineka Cipta

Majid Abdul, (2014). Strategi Pemebelajaran, Bandung : PT Remaja Rosdakarya.

Mulyasa, (2014). Praktik Penelitian Tindakan Kelas. Bandung : PT Remaja Rosdakarya.

Nana Sudjana, (2010). Penilaian Hasil Belajar Proses Belajar Mengajar, Bandung :

PT Remaja Rosdakarya.

Santi Dewiki \& Sri Yuniati, (2013).Ilmu Alamiah Dasar, Jakarta: Universitas Terbuka.

Sardiman. (2012).Interaksi dan Motivasi Belajar Mengajar, Jakarta: PT. Rajagrafindo Persada.

Sri Anitah, dkk, (2012).Strategi Pembelajaran di SD, Jakarta: UT.

Sri Sumarmi, 2011. Perbedaan Hasil Belajar IPA DiTinjau Dari Penggunaan Metode Eksperimen dengan Ceramah Pada kelas IV di SDN Pahandut Tahun Ajaran 2010/2011, Palangkaraya : UMP. 
Jurnal Pendidikan Guru Sekolah Dasar

Sugiyono, (2014). Statistik Untuk

Penelitian, Bandung: CV. Alfabeta , (2016).Metode Penelitian

Pendidikan Pendekatan

Kuantitatif, Kualitatif, dan $R \& D$.

Bandung : Alfabet.

Sardiman,Arief $\quad \mathrm{S}(\mathrm{dkk}) . \quad 2012 . \quad$ Media

Pendidikan,pengembangan dan

Pemanfaatanya. Depok .Rajawali

Pers

Sanjaya Wina. 2013. Media

Pendidikan,Jenis,metode dan

Prosedur. Jakarta .Predana Media

Group.

Patmonodewo. 2013. Teori

Pendidikan,Jenis,metode dan

Prosedur Belajar. Jakarta .Media

Group.

Tim Penyusun, (2014).Buku Pedoman

Penulisan Skripsi, Palangka Raya:

Universitas Muhammadiyah

Palangka Raya.

Wartini Runtuh, 2010. Pengaruh

Penggunaan Metode Eksperimen

Terhadap Hasil Belajar Sains

Peserta Didik SDN-7Bukit Tunggal

Tahun Pembelajaran 2010/2011.

Palangka Raya: Universitas

Muhammadiyah Palangka Raya.

Zainal, Arifin. Evaluasi Pembelajaran.

Bandung : Remaja Rosadakarya. 